\title{
Hybrid Separator-Adsorbent Inorganic Membrane for Oil-Water Separation
}

\author{
Ahmad Kayvani Fard ${ }^{1}$, Gordon McKay ${ }^{2}$, Muataz A. Atieh ${ }^{1}$ \\ ${ }^{1}$ Qatar Environment and Energy Research Institute, Hamad Bin Khalifa University, Qatar Foundation \\ PO Box 5825, Doha, Qatar \\ afard@qf.org.qa; mhussien@qf.org.qa \\ ${ }^{2}$ College of Science and Engineering, Hamad Bin Khalifa University, Qatar Foundation \\ PO Box 5825, Doha, Qatar \\ gmckay@hbku.edu.qa
}

\section{Extended Abstract}

Due to rapid economical and industrial growth across the globe, productions of oil and gas have increased exponentially. As a general rule, when producing a barrel of oil or gas, three barrels of water, so called "produced water" are also associated with this production. Produced water generally contains different contaminants including hydrocarbons, heavy metals, free and emulsified oil, and high salt content [1]. The ratio of oil produced to the produced water in Qatar varies from 1:2 to 1:4 [2]. Totally and from 7 offshore platforms, Qatar produces 241868 barrels/day of oil [2]. Using the 1:2 ratio, minimum of 177 million barrels/ year (483736 barrels/day) of produced water are generated in Qatar.

Different techniques are currently being used in industries for treatment of heavily contaminated produced water from oil/gas industries. Examples of such processes are reverse osmosis, filtration (ultra and micro), various flotation methods (dissolved air, column flotation, electro and induced air), adsorption, gravity separation, activated sludge treatment, membrane bioreactors, biological treatment, chemical coagulation, electro-coagulation and coalescence. Due to operational and economical limitations such as low efficiency, high operational and capital cost, generation of sludge, and inapplicability, they have not been widely accepted and used for the treatment of produced water.

In the present study, we have successfully combined the separation technique using inorganic membrane $\left(\mathrm{Al}_{2} \mathrm{O}_{3}\right)$ with adsorption process using Activated Carbon (AC) as common and cheap adsorbent material in form of a membrane for treatment of produced water. $\mathrm{Al}_{2} \mathrm{O}_{3}$ is very cheap and widely available material on the other hand $\mathrm{AC}$ is also very cheap and usually made of waste generated from food such as coconut shell, rice husk, etc. they Al2O3 and AC are mixed in 10:1 ratio and sintered up to $1150{ }^{\circ} \mathrm{C}$ under inert environment. Although inorganic membranes are generally more expensive compared to polymeric membranes, they have advantages such as withstanding harsh chemical cleaning and frequent backwashing, the ability to be sterilized and autoclaved, high temperature resistance ( up to $500^{\circ} \mathrm{C}$ ) and wear resistance, well-defined and stable pore structure, high chemical stability, and a long life time.

The green membrane showed better surface characteristic such as higher porosity by $30 \%$, and less contact angle. The water contact angle of pure $\mathrm{Al}_{2} \mathrm{O}_{3}$ membrane was estimated to be close to $13 \pm 2.3^{\circ}$. Similar result was reported in the literature [3]. The $\mathrm{Al}_{2} \mathrm{O}_{3} / \mathrm{AC}$ membrane showed superhydrophilicity with a contact angle of almost zero as the high porous structure of membrane cause spreading of the water droplet in fraction of second. In general, ceramic membranes due to presence of hydroxyl $(-\mathrm{OH})$ group on their surface have a hydrophilic surface. Introducing AC which may also contain some - $\mathrm{OH}$ group further reduced the contact angle of $\mathrm{Al}_{2} \mathrm{O}_{3} / \mathrm{AC}$ membrane [4].

To compare the surface roughness, the surface profiler is employed to analyze the surface of the membranes samples. Area of $300 \mu \mathrm{m}$ by $300 \mu \mathrm{m}$ is used to have a representative measurement of the surface roughness. Introduction of AC into the $\mathrm{Al}_{2} \mathrm{O}_{3}$ matrix caused the membrane surface to be more rough compared to the raw membrane. The mean surface roughness of the $\mathrm{Al}_{2} \mathrm{O}_{3}$ and $\mathrm{Al}_{2} \mathrm{O}_{3} / \mathrm{AC}$ membranes are $0.203 \mu \mathrm{m}$ and $2.14 \mu \mathrm{m}$, respectively. The roughness change by the introduction of AC and CNT was also evident from the SEM images (Shown in Figure 1) and these confirm the findings found by surface profiler. It was thought that: introduction of $\mathrm{AC}$ particles into the matrix and due to the size difference between $\mathrm{Al}_{2} \mathrm{O}_{3}$ and carbon material, introduced some valleys between the $\mathrm{Al}_{2} \mathrm{O}_{3}$ particles features, resulting in a rougher 
surface and higher feature height. The increase in roughness may lead to two changes in the membrane which are: an increase of efficient filtration area and a decline in the anti-fouling performance of the membrane [5].
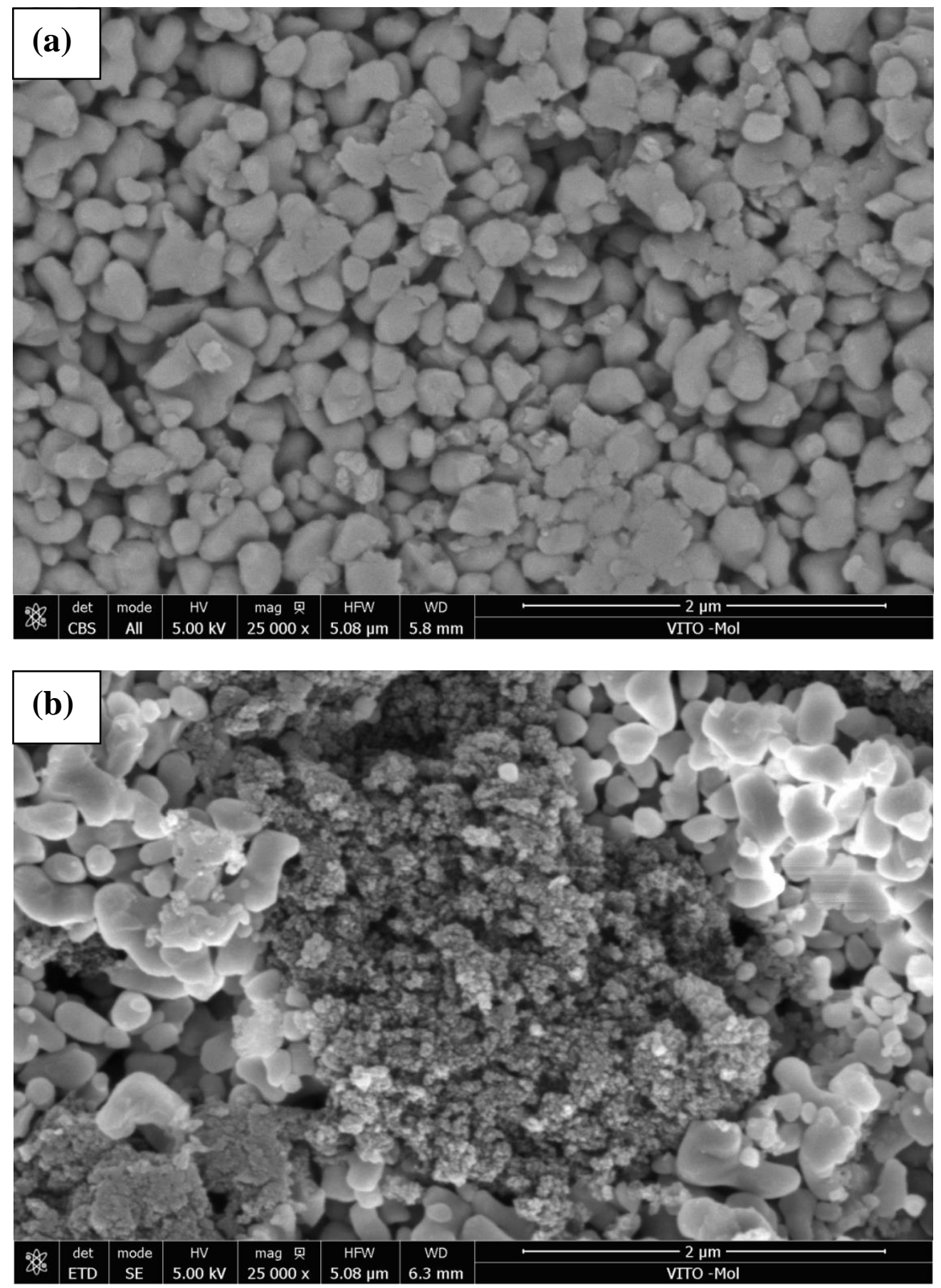

Fig. 1: SEM images of (a) raw Al2O3 membrane and (b) Al2O3 1\% AC membrane.

Also, the membrane showed very promising results with $96 \%$ removal efficiency for emulsified oil and enhanced permeate flux as shown in Figure 2 and Figure 3. 

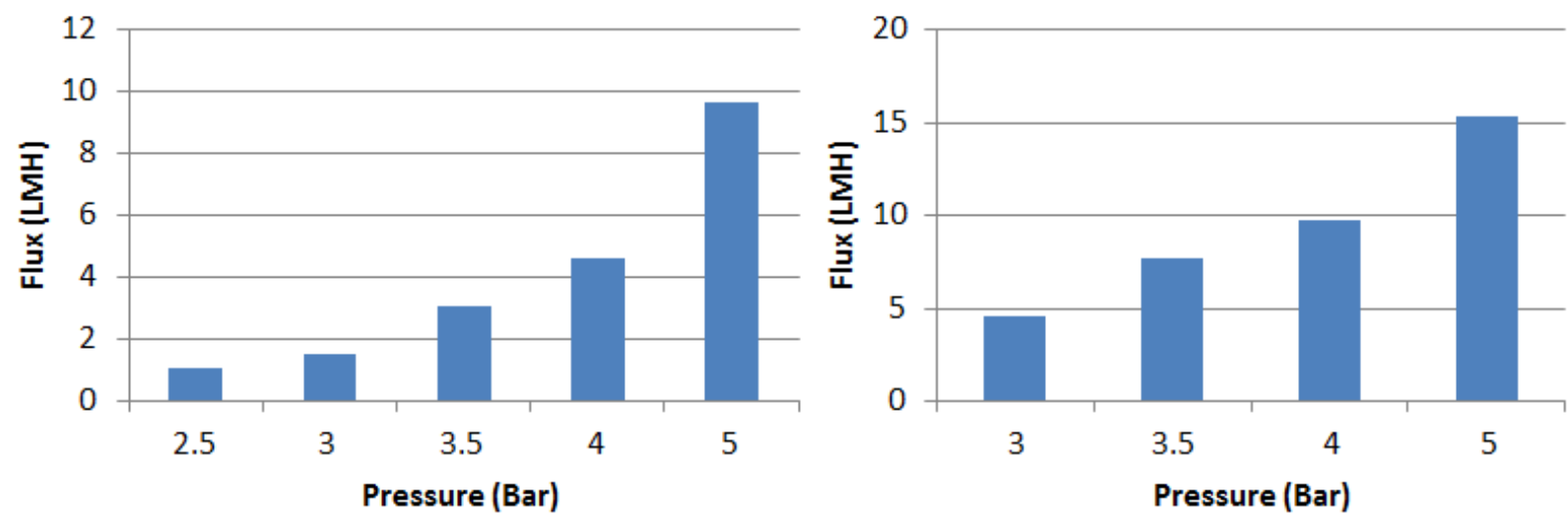

Fig. 2: Pure water flux as function of TMP for (left) raw Al2O3 membrane and (right) Al2O3 1\% AC membrane.

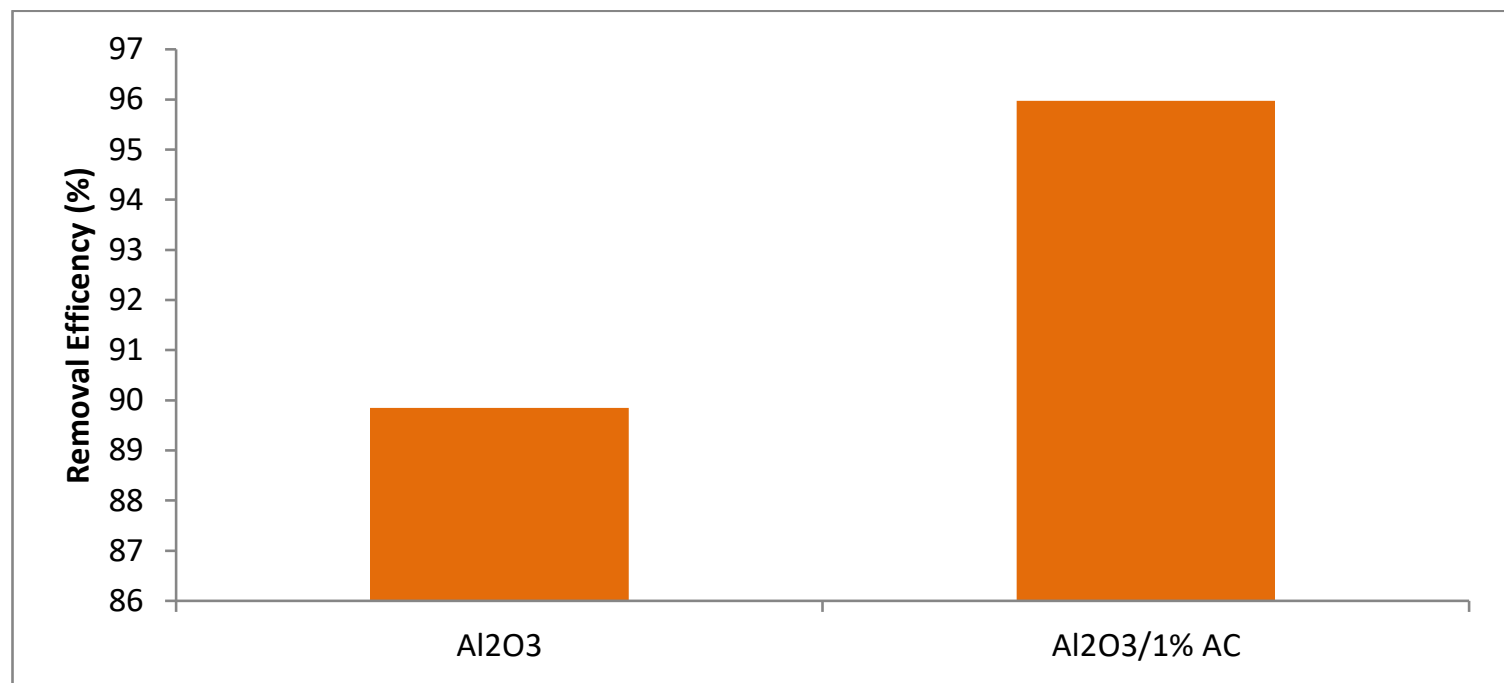

Fig. 3: oil removal efficiency of raw Al2O3 membrane and Al2O3 1\% AC membrane (oil content 2400 ppm).

Effect of salinity on removal was also investigated as shown in Figure 4 on performance of the membrane and it showed to enhance the rejection of oil from the water by salinity increases due to destabilization of emulsion. The membrane is proved to be a good candidate for applications such as treatment of oily wastewater or oil separation from produced water. 


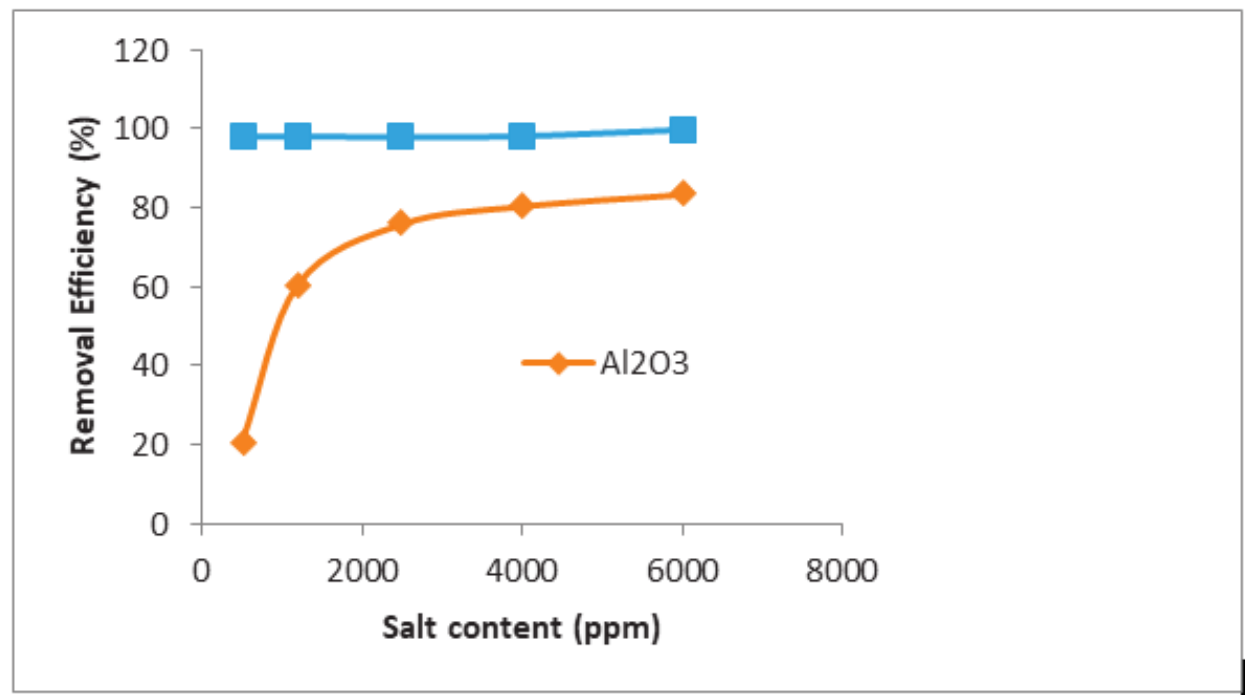

Fig. 4: oil removal efficiency of raw Al2O3 membrane and Al2O3 1\% AC membrane as function of salt content (oil concentration $2400 \mathrm{ppm})$.

\section{References}

[1] Z. Khatib, and P. Verbeek, "Water to value-produced water management for sustainable field development of mature and green fields," in SPE International Conference on Health Safety and Environment in Oil and Gas Exploration and Production, Society of Petroleum Engineers, 2002.

[2] J. A. Ahan, Characterization of Produced Water from Two Offshore Oil Fields in Qatar. 2014.

[3] Q. Zhang, Y. Fan, and N. Xu, "Effect of the surface properties on filtration performance of Al 2 O 3-TiO 2 composite membrane," Separation and Purification Technology, vol. 66, no. 2, pp. 306-312, 2009.

[4] L. Zhu, M. Chen, Y. Dong, C. Y. Tang, A. Huang, and L. Li, "A low-cost mullite-titania composite ceramic hollow fiber microfiltration membrane for highly efficient separation of oil-in-water emulsion," Water research, vol. 90, pp. 277-285, 2016.

[5] L. Yan, Y.S. Li, C.B. Xiang, and S. Xianda, "Effect of nano-sized Al 2 O 3-particle addition on PVDF ultrafiltration membrane performance," Journal of Membrane Science, vol. 276, no. 1, pp. 162-167, 2006. 